\title{
Oncologist Berenter
}

\section{Breast Cancer in Latinas: Gene Expression, Differential Response to Treatments, and Differential Toxicities in Latinas Compared with Other Population Groups}

\author{
Tejal A. Patel,, Gerardo Colon-Otero, ${ }^{\text {a }}$ Celyne Bueno Hume, $\stackrel{\text { a John A. Copland III, }}{\text { b }}$ \\ Edith A. Perez ${ }^{\text {a }}$
}

${ }^{\mathrm{a} D i v i s i o n ~ o f ~ H e m a t o l o g y / O n c o l o g y, ~ M a y o ~ C l i n i c ~ C a n c e r ~ C e n t e r, ~ B r e a s t ~ C l i n i c, ~ J a c k s o n v i l l e, ~ F l o r i d a, ~ U S A ; ~}$

${ }^{\mathrm{b}}$ Cancer Basic Science, College of Medicine, Mayo Clinic, Jacksonville, Florida, USA

Key Words. Access to health care • Breast cancer • Gene expression • Latina • Hispanics

Disclosures: Tejal A. Patel: None; Gerardo Colon-Otero: None; Celyne Bueno Hume: None; John A. Copland III: None; Edith A. Perez: None.

\begin{abstract}
Disparities in clinical outcomes of breast cancer have been described among different racial and ethnic groups in the U.S. Convincing data exist showing that Latina women have a lower incidence of breast cancer but a higher breast cancer-related mortality rate compared with white women. Noticeable differences in breast cancer incidence are present even within different Latina subsets with a higher incidence in secondand third-generation women compared with foreign born. An increasing amount of data exists pointing to significant differences in the genetics and biology of breast cancer in Latinas as a significant contributor to the higher mortality, including a higher incidence of triple-negative breast cancers (which do not overexpress
\end{abstract}

HER-2 protein and are negative for estrogen receptors and progesterone receptors). Other social and environmental factors are likely to play a significant role as well, including a lower rate of screening mammography, variable access to medical care, among others. Recent data are inconclusive regarding differences among racial/ethnic groups in the response to chemotherapy. Data on racial/ethnic variations in the pharmacogenomics of chemotherapy, endocrine treatments, and toxicity are more limited, with some data suggesting differences in frequencies of polymorphisms of genes involved in the metabolism of some of these agents. Further studies are needed on this subject. The Oncologist 2010;15: $466-475$

\section{INTRODUCTION}

Several studies have shown that Hispanics have a lower incidence of breast cancer but a higher mortality rate compared with whites [1,2]. Ethnic-specific studies have the potential to elucidate genetic causes of breast cancer, as illustrated by recent reports of the relationship between gene mutations and differential outcomes of high-risk childhood acute lymphoblastic leukemia in various racial and ethnic groups. These leukemia studies led to the discovery of specific genetic alterations that

Correspondence: Tejal A. Patel, M.D., Division of Hematology/Oncology, Mayo Clinic, 4500 San Pablo Rd, Jacksonville, Florida 32224, USA. Telephone: 904-953-7291; Fax: 904-953-0984; e-mail: patel.tejal@ mayo.edu Received January 4, 2010; accepted for publication March 14, 2010; first published online in The Oncologist Express on April 28, 2010. CAlphaMed Press 1083-7159/2010/\$30.00/0 doi: 10.1634/theoncologist.2010-0004 
are more common in Latino children; these mutations help explain their poorer prognosis and helped introduce targeted therapies that could potentially improve outcomes $[3,4]$.

Latino/Hispanic populations are composed of a very heterogeneous group that includes many different racial and national backgrounds; thus, caution about generalizations is warranted [5]. In the U.S. in 2008, Latinos/Hispanics represented 46.9 million individuals ( $15 \%$ of the overall population) [6]. The majority of these individuals were of Mexican origin (64\%) followed by individuals of Central American or South American origin (14.4\%), Puerto Rican origin (9\%), and Cuban origin (3.5\%) [6]. Marked differences in breast cancer incidence rates exist among the Latina groups. For example, among Latina women in the San Francisco Bay area, the incidence of breast cancer is much higher among second- and third-generation women than among foreign-born women, suggesting a considerable influence from environmental factors [7].

In this article, we present a thorough review of the published literature on breast cancer in Latinas, emphasizing the data on differences in outcomes, differences in breast cancer gene expression, as well as the response to and toxicity of breast cancer treatment in the Latina population. The terms Latina and Hispanic will be used interchangeably.

\section{Differential Overall Outcome of Breast Cancer Among Latina Women}

Breast cancer has a lower incidence rate among Latina women in the U.S. (90.1 cases per 100,000) compared with white women (130.6 per 100,000), although the incidence in Latinas has been increasing over the past 10 years [1,2]. Although the reasons for this increase are unclear, obesity may be a contributing factor [8]. Nevertheless, breast cancer, despite its lower incidence rate, is the most common cancer and the leading cause of cancer death for Latina women. An estimated 14,300 Latina women were diagnosed with breast cancer in 2006, and an estimated 1,740 died of breast cancer in the U.S. in the same year [9]. Studies have attributed this difference in breast cancer outcome between Latinas and white women to several factors: 1) variable access to medical care, resulting in more advanced stage at diagnosis; 2) differing breast cancer risk factors; and 3) differences in genetics and biology. Some newer data are available that address these possible explanations.

\section{Access to Medical Care}

Low socioeconomic status is associated with worse outcome in breast cancer, regardless of ethnic origin. Latina women are more likely to be uninsured, have lower educa- tional achievements, and have higher poverty rates than white women in the U.S.; all of these factors potentially contribute to mortality rate differences [10]. In addition, Latina women are reported to be less likely to be compliant with treatment, probably because of fear associated with the diagnosis and treatment [11]. Language, cultural, and financial barriers may also significantly contribute to a higher noncompliance rate among Latinas [11].

Latina women are more likely to present with advancedstage breast cancer, presumably because of lower use of mammography screening services [10, 12-17]. Elledge et al. [18] reported that a higher percentage of white women present with node-negative breast cancer (55\%) compared with Hispanics (43\%) and blacks (42\%), although no statistically significant differences were observed in overall survival or disease-free survival for patients with nodenegative disease among the different ethnic and racial groups. Fewer white women $(39 \%)$ presented with nodepositive disease or locally advanced breast cancer compared with Hispanics $(50 \%)$ and blacks $(48 \%)(p<.001)$, and significant differences in overall survival $(p=.008)$ and disease-free survival $(p=.001)$ were observed among the racial/ethnic groups [18]. In addition, the proportion of women who presented with distant metastatic disease varied significantly by race (white, 5.4\%; Hispanic, 6.9\%; black, 9.5\%; $p<.001$ ).

Multiple studies have evaluated breast conservation rates and postoperative radiotherapy in blacks, but similar studies in Hispanics are not available at this time. Studies evaluating practice patterns for patients with breast carcinoma who underwent breast conservation surgery showed that only $78.7 \%$ of black and Hispanic women received recommended systemic adjuvant therapy compared with $85.3 \%$ of white women $[19,20]$. However, Elledge et al. [18] reported that for women with node-negative and nodepositive cancers, a greater proportion of Hispanic women received adjuvant chemotherapy compared with black and white women (10\%-20\% more). More white women received endocrine therapy than chemotherapy, but this likely was because of their higher rate of hormone receptor positivity [18].

\section{Differing Breast Cancer Risk Factors}

Although some studies have suggested that socioeconomic factors explain the increased frequency of more advanced stage of breast cancer in black and Hispanic women, most studies to date suggest that black and Latina women have a significantly higher incidence of late-stage breast cancer at presentation even after adjustment for a higher incidence of low socioeconomic status among minorities [21-23]. This suggests that biological and environmental factors specific 
to the minority population are significant contributors to these observed disparities in outcome. The prevalence of established breast cancer risk factors such as reproductive risk factors (e.g., age at first birth, parity, and lactation), use of hormone-replacement therapy, and obesity varies across racial and ethnic subpopulations and likely contributes to the overall increased incidence of breast cancer in white women and to the more advanced-stage cancer at presentation in other ethnic groups. The increase in risk of breast cancer due to reproductive risk factors appears to vary in magnitude as well as pattern in different ethnic/racial groups. For example, nulliparous Hispanic women were found to be at a higher risk of developing breast cancer compared with white women, but increased parity has less of a protective effect on Hispanic women compared with white women [24]. In addition, breastfeeding, which is generally considered relatively protective against subsequent breast cancer, is more so in black and white women compared with Hispanic women [24]. These findings suggest that there may be significant differences in the effects of hormone and other reproductive factors on the causation of breast cancer in Hispanics, which point to the possibility of differences in polymorphisms in genes involved in estrogen metabolism in Hispanics. Further studies in this area are indicated.

A review of factors influencing differences in incidence and outcome of breast cancer in 156,570 postmenopausal women participating in the Women's Health Initiative study showed that black and Latina women had a lower incidence of breast cancer that was explainable by a lower prevalence of known risk factors (age; number of first-degree relatives with breast cancer; age at menarche, first birth, and menopause; and prior breast biopsy for benign breast disease) for breast cancer in minority population [10]. A population-based, case-control study conducted in New Mexico of 694 Hispanic and 813 nonHispanic patients with breast cancer evaluated weight change and body mass index from age 18 to usual adult weight. Weight change and obesity were shown to be risk factors for breast cancer in Hispanic and non-Hispanic white women; however, the risk for Hispanic women was independent of menopausal status, whereas the risk for non-Hispanic women was seen only in postmenopausal women [8].

\section{Differences in Genetics and Biology}

Differences in the genetics and biology of breast cancer are likely to be significant contributors to the disparities in breast cancer outcomes among black and Latina women compared with white women [18]. Elledge et al. [18] evaluated 4,885 white patients, 1,016 black patients, and 777
Hispanic patients with breast cancer and reported significant differences in 5-year survival rates. Five-year survival was $75 \% \pm 1 \%$ for white patients (median survival, 166 months), $70 \% \pm 2 \%$ for Hispanic patients (median, 156 months), and $65 \% \pm 2 \%$ for black patients (median, 117 months). This survival pattern was noted even when evaluating patients with untreated, nonmetastatic disease (Table 1). In a recent study comparing a group of Hispanic women who had the same access to care as white women, more Hispanic women presented with larger, triple-negative breast cancers (these cancers do not overexpress HER-2 protein and are negative for estrogen receptors [ERs] and progesterone receptors $[\mathrm{PRs}]$ ) at a younger age, suggesting that genetic and biologic differences may have a major role in explaining these differences in presentation and outcome [25]. In addition, studies have shown that Latina women with a family history of breast cancer have a markedly higher incidence of breast cancer [26].

Similar to black women, Latina women from Colorado who had the same access to care and same screening mammography rates as non-Hispanic white women were reported to present with breast cancer at a younger age, have a higher incidence of tumors larger than $5 \mathrm{~cm}$ (Table 2), and have a higher incidence of triple-negative tumors (Table 3 ) [18, 25, 27-30]. Using Arizona Cancer Registry data, investigators from the University of Arizona recently published similar findings of a higher incidence of triplenegative breast cancer among Latinas [31]. These findings suggest the presence of influential biologic and possibly genetic differences in breast cancer among Latina women compared with white women. Data on Hispanic women's breast cancer gene microarray analysis including genetic polymorphism analysis, estrogen and progesterone receptor expression, HER-2 receptor gene, BRCA1 and BRCA2 gene expression, and population genetics studies will be reviewed.

\section{Breast Cancer Gene Microarray and Genetic Polymorphism Analysis}

Several studies have shown differences in breast cancer gene expression among Latina women compared with white women, but more work is definitely needed. Most of the studies reported to date have attempted to identify genetic polymorphisms that affect inflammation, ER pathways, and lipid catabolism pathways and to determine their potential role in determining the risk of breast cancer. Studies evaluating the incidence of BRCA1 and BRCA2 mutations in the Hispanic population have also been reported [32]. Gene expression analyses and correlation with breast cancer treatment outcomes in Latinas are lacking in the medical literature. 
Table 1. Comparison of breast cancer mortality in Hispanic, black, and white women

\begin{tabular}{|c|c|c|c|c|c|c|}
\hline \multirow[b]{2}{*}{ Study } & \multicolumn{2}{|c|}{ Hispanic } & \multicolumn{2}{|c|}{ Black } & \multicolumn{2}{|c|}{ White } \\
\hline & $\begin{array}{l}\text { No. of } \\
\text { patients }\end{array}$ & Mortality rate & $\begin{array}{l}\text { No. of } \\
\text { patients }\end{array}$ & Mortality rate & $\begin{array}{l}\text { No. of } \\
\text { patients }\end{array}$ & Mortality rate \\
\hline Jemal et al. [2] & NR & $15.8 / 100,000$ & NR & $33.5 / 100,000$ & NR & $24.4 / 100,000$ \\
\hline Curtis et al. [34] & 1,172 & $\mathrm{HR}, 1.24$ & 2,479 & $\mathrm{HR}, 1.63^{\mathrm{a}}$ & 35,878 & $\mathrm{HR}, 1$ \\
\hline Boyer-Chammard et al. [27] & 875 & HR, 2.3 & 185 & HR, 1.2 & 10,937 & $\mathrm{HR}, 1$ \\
\hline Li et al. [35] & 4,471 & $\mathrm{HR}, 1.3^{\mathrm{a}}$ & 6,915 & $\mathrm{HR}, 2^{\mathrm{a}}$ & 75,978 & $\mathrm{HR}, 1$ \\
\hline O’Malley et al. [36] & 1,100 & HR, 1.39 & 940 & HR, 1.81 & 10,414 & $\mathrm{HR}, 1$ \\
\hline
\end{tabular}

Abbreviations: HR, hazard ratio; NR, not reported.

${ }^{\text {a }}$ Statistically significant difference.

Baumbach et al. [33] recently presented genetic microarray analysis of 28 paraffin-embedded, triple-negative breast cancer samples from Hispanic (10 samples), white ( 8 samples), and black (10 samples) women. For each sample, normal tissue from the same patient was used as control to determine differential gene expression. A total of 9,399 transcripts were expressed in normal tissues from all 3 ethnic groups, and 10,296 transcripts were noted in the tumor tissues. Ethnic-specific expression patterns were observed in both tumor and normal tissue specimens. Significant differential expression of DNA repair pathway genes was observed in tumor samples from all 3 ethnic groups. These studies add further evidence for major differences in gene expression among ethnic groups, which may contribute to the observed disparities in outcome.

On the other hand, a recent single institution study of gene expression in breast cancer did not report any significant differences with regard to clustering of gene expression by ethnicity or genes differentially expressed after adjusting for multiple confounders [37]. This new study evaluated gene expression profiles of 98 triple-negative breast cancer biopsy specimens. These included specimens from 19 black, 23 Hispanic, and 56 white women.

The $\gamma$-aminobutyric acid A receptor is a multisubunit chloride channel that mediates the fastest inhibitory synaptic transmission in the central nervous system. $\gamma$-Aminobutyric acid A receptor, $\pi$ (GABRP) is a type A receptor subunit that is not expressed in normal adult neuronal tissue but is expressed in reproductive and endocrine tissues. Breast tissue undergoes considerable physiologic change during pregnancy and the postpartum period. M.D. Anderson researchers [38] hypothesized that during pregnancy, progenitor cells that coexpress GABRP proliferate within the breast lobules and then are progressively lost during breastfeeding. Therefore, a full-term pregnancy followed by a short duration of lactation may allow survival of progenitor cells, with a higher risk of malignant transformation. Their evaluation of 203 newly diagnosed invasive breast cancers showed that higher GABRP gene expression indeed was more common in younger women with a limited history of lactation after pregnancy. Interestingly, the same study showed that GABRP gene expression was higher in Hispanic women compared with age-matched white controls. The authors suggested that GABRP gene expression may be associated with high-grade breast cancer in Hispanic women; this requires further study.

Slattery et al. [39] reported an analysis of 5 single-nucleotide polymorphisms of the $I L-6$ gene and reported that among postmenopausal women not exposed to exogenous estrogen, the AG/GG genotype of rs1800797 $(-596 \mathrm{~A}>\mathrm{G})$ and the GC/CC genotype of rs1800795 $(-174 \mathrm{G}>\mathrm{C})$ were associated with a significantly lower risk of breast cancer among Hispanic and non-Hispanic white women. Aspirin use among non-estrogen-using Hispanic women was associated with a lower incidence of breast cancer, particularly in carriers of the rs1800796 IL-6 polymorphism.

Vitamin D receptors have a considerable role in modulating transcription of genes involved in calcium and phosphorous homeostasis, as well as those involved in cellular differentiation and proliferation. Polymorphisms in the $5^{\prime}$ and $3^{\prime}$ ends of the vitamin D receptor gene appear to confer phenotypic consequences for calcium and vitamin D metabolism, bone density, and prostate cancer risk [40]. Available data suggest that normal human breast epithelial cells and most breast cancers express the vitamin D receptor. Ingles et al. [40] genotyped polymorphisms in the vitamin D receptor gene for 143 Latina women with breast cancer and 300 controls and reported that polymorphic variation in or near the $3^{\prime}$ end of the vitamin D receptor gene influences breast cancer risk in Latina women.

The genome-wide association studies evaluating genetic polymorphisms and breast cancer risk have not included Hispanic populations [41]. 
Table 2. Tumor characteristics in Hispanic, black, and white women

\begin{tabular}{|c|c|c|c|c|}
\hline Study/Variable & Hispanics & Blacks & Whites & $p$-Value \\
\hline \multicolumn{5}{|l|}{ Chlebowski et al. [10] } \\
\hline No. of patients & 103 & 242 & 3,455 & \\
\hline \multicolumn{5}{|l|}{ Tumor characteristics } \\
\hline Mean size, $\mathrm{cm}$ & 1.89 & 1.60 & 1.56 & .12 \\
\hline Size $2-5 \mathrm{~cm}, \%$ & 15 & 18 & 13 & .58 \\
\hline Size $>5 \mathrm{~cm}, \%$ & 1 & 2 & 2 & .58 \\
\hline Poorly differentiated, $\%$ & 17.7 & 31.8 & 10.0 & $<.001$ \\
\hline \multicolumn{5}{|l|}{ Gapstur et al. [42] } \\
\hline No. of patients & 410 & 1,114 & 11,715 & \\
\hline \multicolumn{5}{|l|}{ Tumor characteristics, $\%$} \\
\hline Size $2-5 \mathrm{~cm}$ & 35 & 38 & 33 & $<.001$ \\
\hline Size $>5 \mathrm{~cm}$ & 9 & 8 & 5 & $<.001$ \\
\hline Positive LN, \% & 41 & 42 & 34 & $<.001$ \\
\hline \multicolumn{5}{|l|}{ Elledge et al. [18] } \\
\hline No. of patients & 777 & 1,016 & 4,885 & \\
\hline \multicolumn{5}{|l|}{ Tumor characteristics, $\%$} \\
\hline Size $2-5 \mathrm{~cm}$ & 51.3 & 42.6 & 44.6 & $<.001$ (all) \\
\hline Size $>5 \mathrm{~cm}$ & 16.6 & 27.7 & 10.9 & $<.001$ (all) \\
\hline \multicolumn{5}{|l|}{ Positive LN, \% } \\
\hline $1-3$ & 24.1 & 24.6 & 21.1 & $<.001(\mathrm{H}$ vs. $\mathrm{W}) ;<.001(\mathrm{~B}$ vs. $\mathrm{W}) ; .31(\mathrm{H}$ vs. $\mathrm{B})$ \\
\hline$>4$ & 30 & 26.6 & 21 & \\
\hline \multicolumn{5}{|l|}{ Li et al. [35] } \\
\hline No. of patients & 7,219 & 10,560 & 97,999 & \\
\hline \multicolumn{5}{|l|}{ Tumor characteristics, $\%$} \\
\hline Size $2-4.9 \mathrm{~cm}$ & 42.8 & 40.7 & 33.5 & NR \\
\hline Size $>5 \mathrm{~cm}$ & 13.9 & 4.6 & 3.3 & NR \\
\hline \multicolumn{5}{|l|}{ Positive LN, \% } \\
\hline $2-4$ & 12.2 & 11.7 & 9.8 & NR \\
\hline$>5$ & 12.6 & 11.6 & 8.7 & NR \\
\hline Tumor grade $3, \%$ & 37.8 & 40.8 & 29.4 & NR \\
\hline \multicolumn{5}{|l|}{ Hausauer et al. [43] } \\
\hline No. of patients & 15,355 & 19,105 & 193,513 & \\
\hline Tumor size $>2 \mathrm{~cm}, \%$ & 43.5 & 45.6 & 34.4 & NR \\
\hline \multicolumn{5}{|l|}{ Shavers et al. [44] } \\
\hline No. of patients & 616 & 724 & 2,638 & \\
\hline Median tumor size, $\mathrm{cm}$ & 3 & 2.8 & 2.5 & $<.001$ \\
\hline \multicolumn{5}{|l|}{ Positive LN, \% } \\
\hline $1-3$ & 23.4 & 22.4 & 21.1 & NR \\
\hline $4-10+$ & 11.5 & 12.4 & 9.3 & .004 \\
\hline Tumor grade $3, \%$ & 51.5 & 54.8 & 43.3 & $<.001$ \\
\hline
\end{tabular}

\section{ER and PR Status}

Few studies have evaluated the association between race/ ethnicity and tumor expression of ER and PR after adjusting for other tumor biologic characteristics. In general, Hispanic patients with breast cancer tend to have ER-negative tumors more frequently than non-Hispanic white women, 
Table 3. Comparison of ER status in Hispanic, black, and white women

\begin{tabular}{|c|c|c|c|c|c|c|}
\hline \multirow[b]{2}{*}{ Study } & \multicolumn{2}{|c|}{ Hispanic } & \multicolumn{2}{|c|}{ Black } & \multicolumn{2}{|c|}{ White } \\
\hline & $\begin{array}{l}\text { No. of } \\
\text { patients }\end{array}$ & $\begin{array}{l}\text { ER negative, } \\
\%\end{array}$ & $\begin{array}{l}\text { No. of } \\
\text { patients }\end{array}$ & $\begin{array}{l}\text { ER negative, } \\
\%\end{array}$ & $\begin{array}{l}\text { No. of } \\
\text { patients }\end{array}$ & $\begin{array}{l}\text { ER negative, } \\
\%\end{array}$ \\
\hline Elledge et al. [18] & 777 & 29.9 & 1,016 & 37.9 & 4,885 & 22.1 \\
\hline Chlebowski et al. [10] & 103 & 17 & 242 & 29 & 3,455 & 13 \\
\hline Dunnwald et al. [45] & 5,585 & 29.8 & 5,724 & 39.5 & 78,805 & 21.6 \\
\hline Chu et al. [46] & 9,860 & 21.1 & 7,896 & 26.4 & 96,272 & 17.3 \\
\hline Li et al. [35] & 4,471 & 24.1 & 6,915 & 33.7 & 75,978 & 18.8 \\
\hline Hausauer et al. [43] & 15,355 & 17.3 & 19,105 & 24.2 & 193,513 & 14.2 \\
\hline Gapstur et al. [42] & 410 & 30 & 1,114 & 42 & 11,715 & 26 \\
\hline
\end{tabular}

although the difference was not as great as that seen between black and non-Hispanic white women [47]. Elledge et al. [18] also showed that ER-negative tumors were more common in Hispanic patients with breast cancer compared with non-Hispanic patients $(29.9 \%$ vs. $22.1 \%$; $p<.0001)$ but less frequent than in black women $(29.9 \%$ vs. $37.9 \%$; $p<.0001)$. Another study used data from 13 Surveillance, Epidemiology, and End Results cancer registries over a study period from 1992 through 2004 [43]. Researchers analyzed age-adjusted incidence rates and trends from women older than 50 years, stratified by race or ethnicity and tumor subtype, and showed an increase in incidence rates of ERand PR-negative tumors among Hispanic women compared with white women $(14.2 \%$ in white women compared with $17.3 \%$ in Hispanic women). They reported a relative increase in rates (cases per 100,000 person-years) of triplenegative breast cancer in Hispanic women (from 2001 through 2004) of $26.8 \%$, with an absolute increase from 34.6 (95\% confidence interval [CI], 29.9-39.9) to 43.9 (95\% CI, 39.0-49.9) [43].

\section{HER-2 Receptor Status}

In general, $10 \%$ to $15 \%$ of breast cancers are HER-2 positive, as determined by protein overexpression or gene amplification [48]. Bauer et al. [49] used the population-based California Cancer Registry to analyze the triple-negative phenotype. They showed that the most powerful risk factors for the triple-negative subtype were age younger than 40 years, non-Hispanic black race, and, to a lesser extent, Hispanic race (hazard ratio [HR] for non-Hispanic blacks, 1.77 [95\% CI, 1.59-1.97]; for Hispanics, 1.23 [95\% CI, 1.141.34]). Elledge et al. [18] did not observe any significant differences in the frequency of HER-2-positive breast cancers in patients of different ethnic/race groups.

Increased activation of the AKT1 gene (also termed
$A K T$ ) has been associated with HER-2/neu overexpression and with worse outcomes. In a recent analysis by Wu et al. [50], more than $70 \%$ of black and Latina women with HER2/neu-positive tumors had overexpression of $A K T 1$. In contrast, only $43 \%$ to $44 \%$ of Japanese and Swedish women with HER-2/neu-positive tumors had increased AKT1 expression.

\section{BRCA1 and BRCA2 Mutations}

Among the nonwhite minorities, Hispanics with breast cancer have the highest incidence of pathogenic BRCAl mutations [32]. In a report of data collected from the Breast Cancer Family Registry of women younger than 65 years with breast cancer enrolled at the Northern California site, prevalence of the $B R C A 1$ mutation was $3.5 \%$ for Hispanics, $1.3 \%$ for blacks, $0.5 \%$ for Asian Americans, $8.3 \%$ for Ashkenazi Jews, and $2.2 \%$ for other non-Hispanic whites. The authors postulated that the higher prevalence of the BRCAl mutations among Hispanics may reflect a higher incidence of Jewish ancestry in this subset [32]. Given the higher incidence of triple-negative breast cancer among carriers of pathogenic BRCA1 mutations, this particular genetic factor may heavily contribute to the described disparities in breast cancer outcome.

Large genetic rearrangements account for $8 \%$ to $15 \%$ of $B R C A$ mutations. Recently, a deletion involving exons 9 through 12 of $B R C A l$ was identified in 5 unrelated Mexican families that did not have an identifiable $B R C A$ mutation [51]. The authors suggest that an assay for this mutation should be considered for sequence-negative, high-risk Hispanic patients. A large multiplex panel that tests for $18 \mathrm{mu}-$ tations in $B R C A 1$ and $B R C A 2$, which would replace complete sequencing of the BRCA genes, is currently being developed. 


\section{Population Genetics}

Most individuals of Hispanic ancestry have genetic backgrounds that combine 2 of 3 different populations: European, African, and Native American [52]. Among Latinas in the San Francisco Bay area, women with a greater European background had a higher incidence of breast cancer [52]. In addition, marked differences between Mexicanborn women and U.S.-born Mexican American women have been described recently [53]. In that study, 652 women were recruited ( 309 from the U.S. and 343 from Mexico). The women differed with respect to the age at diagnosis of breast cancer (average age 48.7 years in the U.S. vs. 53.8 years in Mexico), number of live births (3.2 in the U.S. vs. 3.7 in Mexico), and the prevalence of family history of breast cancer $(18.1 \%$ in the U.S. vs. $6.2 \%$ in Mexico).

The 4-Corners Breast Study is a case-control, population-based study of women in the southwestern U.S. The study enrolled 3,074 non-Hispanic white women and 1,674 Hispanic women. Findings from this study have suggested that genetics may significantly influence the disparities observed in breast cancer outcome in the Hispanic population. This study examined those with a family history of breast cancer and showed that Hispanic women had a higher incidence of triple-negative breast cancer, whereas nonHispanic white women had a higher incidence of postmenopausal hormone receptor-positive breast cancer [54]. Among women younger than 50 years, a family history of breast cancer was associated with a higher risk of breast cancer among non-Hispanic whites compared with Hispanics, suggesting a stronger genetic predisposition among white women [55]. This difference in risk was not observed among older women in the study; for those women, a family history of breast cancer was associated with a similar risk of breast cancer for Hispanic and non-Hispanic white women [55].

\section{Differential ReSPONSE to TREATMENT}

\section{Chemotherapy}

A number of studies have examined the differential responses and survival outcomes among women of different racial groups (especially black women) in response to chemotherapy and have shown conflicting results. After controlling for numerous factors, including socioeconomic status, most trials show that chemotherapy treatments have comparable efficacy among patients with breast cancer, at least when comparing blacks with whites [56]. This was further shown in a recent M.D. Anderson Cancer Center study, which demonstrated similar responses to chemotherapy in the neoadjuvant setting in black and white women
[57]. An older study with a small number of patients $(n=$ 37) reported that different ethnic groups of poor urban women with locally advanced breast cancer did not significantly differ in their response to adjuvant chemotherapy with cyclophosphamide, methotrexate, and 5-fluorouracil or with 5-fluorouracil, doxorubicin, and cyclophosphamide plus radiotherapy [58]. Another study evaluated neoadjuvant chemotherapy and pathologic complete response to anthracycline- and taxane-based neoadjuvant chemotherapy in patients with stage II and III breast cancer [59]. Of 2,074 total patients, $14.6 \%$ were black, $15.2 \%$ Hispanic, $64.3 \%$ white, and $5.9 \%$ other. There was no differences in pathologic complete response rates among racial/ethnic group (12.5\% in blacks, $14.24 \%$ in Hispanics, $12.3 \%$ in whites, and $11.5 \%$ others, $p=0.788$ ). Although authors concluded that race/ethnicity was not a predictor of survival outcome, there appeared to be a trend toward improvement in relapse-free survival (HR 0.69 [95\% CI 0.49-0.97]) and overall survival (HR 0.63 [95\% CI 0.41-0.97]) in Hispanic women [59].

Contrary to the above studies, when racial disparities in survival were evaluated in 19,457 participants of Southwest Oncology Group trials, Albain et al. found that black patients had worse survival than white patients for early-stage premenopausal and postmenopausal breast cancer, advanced staged ovarian cancer, and advanced stage prostate cancer [60]. No statistically significant association between race and survival was seen for lung cancer, colon cancer, lymphoma, leukemia, or myeloma [60]. Another study, reported by Balmanoukian et al. [61], included 38 patients and showed a lower pathologic complete response in black patients compared with women in the white/other group.

Most studies have not been sufficiently powered to determine whether specific treatments have different efficacy and whether survival in minority populations differs from the overall survival of the study group.

\section{Antiestrogen Therapy}

Tamoxifen is extensively metabolized to several primary and secondary metabolites, including 4-hydroxytamoxifen and endoxifen, by various cytochrome $\mathrm{P} 450$ genes such as CYP2D6 and CYP2C9. A recent study evaluated clinical data and blood samples from 301 patients (299 females, 2 males) who received at least 8 weeks of adjuvant tamoxifen therapy [62]. Most patients were white (68\%) or Hispanic $(26 \%)$. Hispanics had significantly higher serum levels of tamoxifen $(p=.02)$ and 4-hydroxytamoxifen $(p=.007)$ than whites.

Polymorphisms have been identified in the genes encoding a number of cytochrome P450 enzymes that lead to variable drug clearance rates. Considerable ethnic differ- 
ences in the CYP2D6 allele frequencies have been reported [63]. CYP2D6 polymorphisms can be classified according to one of four metabolizer activity levels-poor, intermediate, extensive, and ultrarapid. Strong association was seen between CYP2D6 activity and plasma levels of endoxifen. The extensive metabolizer phenotype is expressed by most people and is considered the normal phenotype. The prevalence of the poor metabolizer phenotype in the Hispanic population is reported to be $2.2 \%$ to $6.6 \%$; in whites, it is $8.9 \%$ to $10 \%$; and in Asians, it is $0 \%$ to $1.2 \%$.

Human sulfotransferase 1A1 (SULT1A1) is an enzyme involved in the metabolism of 4-hydroxytamoxifen. Homozygosity for $S U L T I A 1 * 2 / * 2$ leads to lower catalytic activity [64]. Nowell et al. [65] have shown that patients with breast cancer who were treated with tamoxifen and were homozygous for the $S U L T 1 A 1 * 2$ allele had increased risk of death compared with those who were homozygous or heterozygous for $S U L T I A I * 1$ [65]. Grabinski et al. [64] showed that Hispanics have a higher genotypic frequency of the $* 2 / * 2$ variant genotype compared with whites, although the difference was not statistically significant.

\section{Differential Toxicity Related To Treatment}

\section{Chemotherapy}

Unfortunately, the data are very limited with regard to differences in toxicity from treatment of breast cancer in different ethnic and racial groups. Han et al. [66] recently reviewed toxicity data among different ethnic groups after neoadjuvant chemotherapy with 5-fluorouracil, epirubicin, and cyclophosphamide. Significantly higher hematologic toxicity was observed in Asian women from Japan and Hong Kong compared with white and black women. Their analysis did not include Hispanic women. Some data report lower white blood cell counts in black women, which may contribute to delays in chemotherapy or dose reductions [20].

\section{Antiestrogen Therapy}

Differences in the incidence of polymorphisms of the aromatase gene among different ethnic groups have been reported [67]. These differences may lead to differential toxicity among ethnic groups. The MA.17 trial [68] studied postmenopausal women with hormone receptor-positive breast cancer who had completed 5 years of tamoxifen therapy. Study investigators compared data from 5 years of adjuvant aromatase inhibitor therapy versus placebo and showed that women of minority backgrounds were less likely to have toxicity from aromatase inhibitors. However, the beneficial effect of aromatase inhibitor therapy also was not observed in the subset of minority women. A significantly greater number of minority women reported not taking the letrozole daily. Latina women represented $1.5 \%$ of the participants in that study.

\section{Conclusion}

Differences in the incidence and outcome of breast cancer among Latina women compared with white women are well documented in the medical literature and likely explained by issues of access to medical care, different incidence of environmental factors including known breast cancer risk factors, and differences in genetics and biology of breast cancer. Data on the pharmacogenomics of chemotherapy and endocrine therapy response and toxicity are more limited, but some data do suggest differences in frequencies of polymorphisms involved in the metabolism of some of these agents. Further studies elucidating the pathogenesis of these differences are very important because they may lead to genetic discoveries with potentially significant therapeutic implications.

\section{Author Contributions}

Conception/design: Gerardo Colon-Otero

Collection/assembly of data: Tejal A. Pate

Manuscript writing: Tejal A. Patel, Gerardo Colon-Otero, Celyne Bueno Hume

Final approval of manuscript: Tejal A. Patel, Gerardo Colon-Otero, Celyne Bueno Hume, John A. Copland III, Edith Perez

\section{REFERENCES}

1 Hunter CP. Epidemiology, stage at diagnosis, and tumor biology of breast carcinoma in multiracial and multiethnic populations. Cancer 2000;88(5 suppl):1193-1202.

2 Jemal A, Siegel R, Ward E et al. Cancer statistics, 2009. CA Cancer J Clin 2009;59:225-249.

3 Harvey RC. Rearrangement of CRLF2 in associated with mutations of JAK2 kinases, alterations of IKZF1, Hispanic/Latino ethnicity, and a poor outcome in pediatric B-progenitoracute lymphoblastic leukemia. Blood 2010 [Epub ahead of print].

4 Yang JJ. Genome-wide interrogation of germline genetic variation associ- ated with treatment response in childhood acute lymphoblastic leukemia. JAMA 2009;301:393-403.

5 Ramirez AG, Talavera GA, Villarreal R et al. Breast cancer screening in regional Hispanic populations. Health Educ Res 2000;15:559-568.

6 U. S. Census Bureau. Facts for Features: Hispanic Heritage Month 2009 (CB09-44.17). Available at http://www.census.gov/Press-Release/www/ releases/archives/facts_for_features_special_editions/013984.html, accessed July 15, 2009.

7 John EM, Phipps AI, Davis A et al. Migration history, acculturation, and breast cancer risk in Hispanic women. Cancer Epidemiol Biomarkers Prev 2005;14:2905-2913.

8 Wenten M, Gilliland FD, Baumgartner K et al. Associations of weight, 
weight change, and body mass with breast cancer risk in Hispanic and nonHispanic Caucasian women. Ann Epidemiol 2002;12:435-434.

9 American Cancer Society. Cancer Facts \& Figures for Hispanics/Latinos 2006-2008. Atlanta: American Cancer Society; 2006.

10 Chlebowski RT, Chen Z, Anderson GL et al. Ethnicity and breast cancer: factors influencing differences in incidence and outcome. J Natl Cancer Inst 2005;97:439-448.

11 Mack KP, Pavao J, Tabnak F et al. Adherence to recent screening mammography among Latinas: findings from the California Women's Health Survey. J Womens Health (Larchmt) 2009;18:347-354.

12 Bentley JR, Delfino RJ, Taylor TH et al. Differences in breast cancer stage at diagnosis between non-Hispanic Caucasian and Hispanic populations, San Diego County 1988-1993. Breast Cancer Res Treat 1998;50:1-9.

13 Daly MB, Clark GM, McGuire WL. Breast cancer prognosis in a mixed Caucasian-Hispanic population. J Natl Cancer Inst 1985;74:753-757.

14 Gapstur SM, Lopez P, Colangelo LA. Sociodemographic and cultural factors associated with mammography screening among Latina women. J Women Cancer 2005;5:1-8.

15 Hedeen AN, Caucasian E. Breast cancer size and stage in Hispanic American women, by birthplace: 1992-1995. Am J Public Health 2001;91:122125 .

16 Mandelblatt J, Andrews H, Kerner J et al. Determinants of late stage diagnosis of breast and cervical cancer: the impact of age, race, social class, and hospital type. Am J Public Health 1991;81:646-649. [Erratum in: Am J Public Health 1991;81:980.]

17 Natarajan N, Nemoto T, Mettlin C et al. Race-related differences in breast cancer patients: results of the 1982 national survey of breast cancer by the American College of Surgeons. Cancer 1985;56:1704-1709.

18 Elledge RM, Clark GM, Chamness GC et al. Tumor biologic factors and breast cancer prognosis among Caucasian, Hispanic, and black women in the United States. J Natl Cancer Inst 1994;86:705-712.

19 Caucasian J, Morrow M, Moughan J et al. American College of Surgeons Commission on Cancer; American College of Radiology Patterns of Care Study. Compliance with breast-conservation standards for patients with early-stage breast carcinoma. Cancer 2003;97:893-904.

20 Newman LA, Martin IK. Disparities in breast cancer. Curr Probl Cancer 2007;31:134-156.

21 Lantz PM, Mujahid M, Schwartz K et al. The influence of race, ethnicity, and individual socioeconomic factors on breast cancer stage at diagnosis. Am J Public Health 2006;96:2173-2178.

22 Richardson JL, Langholz B, Bernstein L et al. Stage and delay in breast cancer diagnosis by race, socioeconomic status, age and year. $\mathrm{Br} \mathrm{J}$ Cancer 1992;65:922-926.

23 Roetzeim RG, Pal N, Tennant C et al. Effects of health insurance and race on early detection of cancer. J Natl Cancer Inst 1999;91:1409-1415.

24 Gilliland FD, Hunt WC, Baumgartner KB et al. Reproductive risk factors for breast cancer in Hispanic and non-Hispanic Caucasian women: the New Mexico Women's Health Study. Am J Epidemiol 1998;148:683-692.

25 Watlington AT, Byers T, Mouchawar J et al. Does having insurance affect differences in clinical presentation between Hispanic and non-Hispanic Caucasian women with breast cancer? Cancer 2007;109:2093-2099.

26 Li R, Gilliland FD, Baumgartner KB et al. Family history and risk of breast cancer in hispanic and non-hispanic women: the New Mexico Women's Health Study. Cancer Causes Control 2001;12:747-753.

27 Boyer-Chammard A, Taylor TH, Anton-Culver H. Survival differences in breast cancer among racial/ethnic groups: a population-based study. Cancer Detect Prev 1999;23:463-473.
28 Carey LA, Perou CM, Livasy CA et al. Race, breast cancer subtypes, and survival in the Carolina Breast Cancer Study. JAMA 2006;295:2492-2502.

29 Setiawan VW, Monroe KR, Wilkens LR et al. Breast cancer risk factors defined by estrogen and progesterone receptor status: the multiethnic cohort study. Am J Epidemiol 2009;169:1251-1259.

30 Zaloznik AJ. Breast cancer stage at diagnosis: Caucasians versus Hispanics. Breast Cancer Res Treat 1997;42:121-124.

31 Martinez ME, Nielson CM, Nagle R et al. Breast cancer among Hispanic and non-Hispanic Caucasian women in Arizona. J Health Care Poor Underserved 2007;18(4 suppl):130-145.

32 John EM, Miron A, Gong G et al. Prevalence of pathogenic BRCA1 mutation carriers in 5 US racial/ethnic groups. JAMA 2007;298:2869-2876.

33 Baumbach L, Ahearn ME, Jorda M et al. Multi-ethnic comparisons of genome-wide alterations in breast cancer using paraffin embedded samples. Presented at: Annual Meeting of the American Society of Human Genetics; October 23-27, 2007; San Diego.

34 Curtis E, Quale C, Haggstrom D et al. Racial and ethnic differences in breast cancer survival: how much is explained by screening, tumor severity, biology, treatment, comorbidities, and demographics? Cancer 2008;112: $171-180$.

35 Li CI, Malone KE, Daling JR. Differences in breast cancer stage, treatment, and survival by race and ethnicity. Arch Intern Med 2003;163:49-56.

36 O’Malley CD, Le GM, Glaser SL et al. Socioeconomic status and breast carcinoma survival in four racial/ethnic groups: a population-based study. Cancer 2003;97:1303-1311

37 Dean-Colomb W, Yan K, Liedtke C et al. Transcriptional profiles on triple receptor-negative breast cancer: are Caucasian, Hispanic, and AfricanAmerican women different [abstract]? J Clin Oncol 2008;15S:22014

38 Symmans WF, Fiterman DJ, Anderson SK et al. A single-gene biomarker identifies breast cancers associated with immature cell type and short duration of prior breastfeeding. Endocr Relat Cancer 2005;12:1059-1069.

39 Slattery ML, Curtin K, Baumgartner R et al. IL6, aspirin, nonsteroidal antiinflammatory drugs, and breast cancer risk in women living in the southwestern United States. Cancer Epidemiol Biomarkers Prev 2007;16:747755 .

40 Ingles SA, Garcia DG, Wang W et al. Vitamin D receptor genotype and breast cancer in Latinas (United States). Cancer Causes Control 2000;11: $25-30$.

41 Dunning AM, Healey CS, Pharoah PD et al. A systematic review of genetic polymorphisms and breast cancer risk. Cancer Epidemiol Biomarkers Prev $1999 ; 8: 843-854$

42 Gapstur SM, Dupuis J, Gann P et al. Hormone receptor status of breast tumors in black, Hispanic, and non-Hispanic Caucasian women: an analysis of 13,239 cases. Cancer 1996;77:1465-1471.

43 Hausauer AK, Keegan TH, Chang ET et al. Recent breast cancer trends among Asian/Pacific Islander, Hispanic, and African-American women in the US: changes by tumor subtype Breast. Cancer Res 2007;9:R90.

44 Shavers VL, Harlan LC, Stevens JL. Racial/ethnic variation in clinical presentation, treatment, and survival among breast cancer patients under age 35. Cancer 2003;97:134-147.

45 Dunnwald LK, Rossing MA, Li CI. Hormone receptor status, tumor characteristics, and prognosis: a prospective cohort of breast cancer patients. Breast Cancer Res 2007;9:R6.

46 Chu KC, Anderson WF, Fritz A et al. Frequency distributions of breast cancer characteristics classified by estrogen receptor and progesterone receptor status for eight racial/ethnic groups. Cancer 2001;92:37-45.

47 Vona-Davis L, Rose DP. The influence of socioeconomic disparities on 
breast cancer tumor biology and prognosis: a review. J Womens Health (Larchmt) 2009;18:883-893.

48 Perez EA, Roche PC, Jenkins RB et al. HER2 testing in patients with breast cancer: poor correlation between weak positivity by immunohistochemistry and gene amplification by fluorescence in situ hybridization. Mayo Clin Proc 2002;77:148-154.

49 Bauer KR, Brown M, Cress RD et al. Descriptive analysis of estrogen receptor (ER)-negative, progesterone receptor (PR)-negative, and HER2negative invasive breast cancer, the so-called triple-negative phenotype: a population-based study from the California Cancer Registry. Cancer 2007; 109:1721-1728.

$50 \mathrm{Wu}$ Y, Mohamed H, Chillar R et al. Clinical significance of Akt and HER2/ neu overexpression in African-American and Latina women with breast cancer. Breast Cancer Res 2008;10:R3.

51 Weitzel JN, Lagos VI, Herzog JS et al. Evidence for common ancestral origin of a recurring BRCA1 genomic rearrangement identified in high-risk Hispanic families. Cancer Epidemiol Biomarkers Prev 2007;16:16151620.

52 Fejerman L, John EM, Huntsman S et al. Genetic ancestry and risk of breast cancer among U.S. Latinas. Cancer Res 2008;68:9723-9728.

53 Meza MM, Martinez ME, Thompson P et al. The Ella Binational Breast Cancer Study: risk factor and tumor marker profile in women of Mexican ancestry. Presented at: American Association for Cancer Research Conference on the Science of Cancer Health Disparities in Racial/Ethnic Minorities and the Medically Underserved; February 3-6, 2009; Carefree, AZ.

54 Hines LM, Risendal B, Slattery ML et al. Differences in estrogen receptor subtype according to family history of breast cancer among Hispanic, but not non-Hispanic Caucasian women. Cancer Epidemiol Biomarkers Prev 2008; 17:2700-2706.

55 Risendal B, Hines LM, Sweeney C et al. Family history and age at onset of breast cancer in Hispanic and non-Hispanic Caucasian women. Cancer Causes Control 2008;19:1349-1355.

56 Muss HB. Factors used to select adjuvant therapy of breast cancer in the United States: an overview of age, race, and socioeconomic status. J Natl Cancer Inst Monogr 2001;(30):52-55.

57 Dawood S, Broglio K, Kau SW et al. Triple receptor-negative breast can- cer: the effect of race on response to primary systemic treatment and survival outcomes. J Clin Oncol 2009;27:220-226.

58 Boddie AW, Warso M, Briele H et al. Multimodal-therapy breast salvage in the urban poor with locally advanced cancer. Arch Surg 1996;131:424429.

59 Chavez-Mac Gregor M, Litton J, Huiquin C et al. Race and pathologic complete response $(\mathrm{pCR})$ in breast cancer patients receiving anthracycline and taxane-based neoadjuvant chemotherapy. Presented at: Breast Cancer Symposium; October 8-10, 2009; San Francisco.

60 Albain KS, Unger JM, Crowley JJ et al. Racial disparities in cancer survival among randomized clinical trials patients of the Southwest Oncology Group. J Natl Cancer Inst 2009;101:984-992.

61 Balmanoukian A, Zhang Z, Jeter S et al. African American women who receive primary anthracycline- and taxane-based chemotherapy for triplenegative breast cancer suffer worse outcomes compared with Caucasian women. J Clin Oncol 2009;27:e35-e37.

62 Grabinski JL, Smith LS, Chisholm GB et al. Relationship between CYP2D6 and estrogen receptor alpha polymorphisms on tamoxifen metabolism in adjuvant breast cancer treatment [abstract]. J Clin Oncol 2006;18S: 505.

63 Bernard S, Neville KA, Nguyen AT et al. Interethnic differences in genetic polymorphisms of CYP2D6 in the U.S. population: clinical implications. Oncologist 2006;11:126-135.

64 Grabinski JL, Smith LS, Chisholm GB et al. Genotypic and allelic frequencies of SULT1A1 polymorphisms in women receiving adjuvant tamoxifen therapy. Breast Cancer Res Treat 2006;95:13-16.

65 Nowell SA, Ahn J, Rae JM et al. Association of genetic variation in tamoxifen-metabolizing enzymes with overall survival and recurrence of disease in breast cancer patients. Breast Cancer Res Treat 2005;91:249-258.

66 Han HS, Reis I, Kuroi K et al. Racial differences in acute toxicities of adjuvant chemotherapy in patients with breast cancer. Presented at: Breast Cancer Symposium; September 5-7, 2008; Washington.

67 Ma CX, Adjei AA, Salavaggione OE et al. Human aromatase: gene resequencing and functional genomics. Cancer Res 2005;65:11071-11082.

68 Moy B, Tu D, Pater JL et al. Clinical outcomes of ethnic minority women in MA.17: a trial of letrozole after 5 years of tamoxifen in postmenopausal women with early stage breast cancer. Ann Oncol 2006;17:1637-1643. 